\title{
WEAVING THE KNOWLEDGE CAPABILITIES, SUPPLY CHAIN MANAGEMENT SKILLS AND COPING CAPACITY INTO THE FABRIC OF SUPPLY CHAIN DECISION MAKERS: A CONCEPTUAL FRAMEWORK
}

\author{
Lay Kheng Khor ${ }^{1,}$, Cheng Ling Tan ${ }^{1}$ \\ ${ }^{1}$ Graduate School of Business, Universiti Sains Malaysia, 11800 Pulau Pinang, Malaysia.
}

ABSTRACT - The recent global outbreak of COVID-19 has created a huge global crisis, breaking down many global supply chains. Decision makers in the supply chain are faced with very challenging situation as the application of supply chain resilience mechanisms are questionable and unreliable during the post pandemic. Hence, leaving them to continue learning new ways to cope, adapt and mitigate the risk to navigate through the uncertainties. This imply that knowledge, skills, abilities and competencies of decision makers have become the centre stage for organizations' survival and sustainability. The purpose of this paper is to identify the key factors that influence decision making competency in the supply chain of the Malaysian manufacturing firms. This is a conceptual paper focusing on developing a research framework through the integration of the behavioural decisional theory and competency model. The research framework with respect to the construct of decision making competency are elaborated. This paper hopes to provide a valuable pragmatic framework and insight for managerial decision making in the context of supply chain. By understanding the supply chain decision making in operations, this can help to contribute to de-risking of supply chain beyond the usual risk response into the proactive reduction of risks for future supply chain sustainability.

\author{
ARTICLE HISTORY \\ Received: 29-8-2021 \\ Revised: 20-10-2021
}

Accepted: 25-11-2021

KEYWORDS

Decisi-Making

Competency

Knowledge

Capabilities

Supply Chain

Management Skill

Coping Capacity

\section{INTRODUCTION}

The unprecedented Coronavirus COVID-19 has a tandem effect on both health and the economy globally and locally. In early March 2020, the number of COVID-19 cases has grown exponentially worldwide, resulting in border closures, quarantines, restricted domestic travel, and an entirely complete shutdown of many crucial facilities, markets, and activities in the supply chain. Moreover, different supply chain components are affected sequentially or concurrently, specifically in manufacturing, distribution centres, logistics and markets can become paralysed within overlapping time windows (Ivanov \& Das, 2020). Consequently, supply availability in global supply chains has been drastically reduced and misbalanced with the demands, which have caused a massive global crisis of breaking many global supply chains (Araz et al., 2020).

The ongoing COVID-19 crisis has also pushed organisations worldwide to rapidly operate in newer and more resilient ways to navigate the uncertainties ahead of them. Hence, modifying existing supply chain measures is one of the most important aspects of coping with risks to ensure business continuity while dealing with the COVID-19 crisis (Verma \& Gustafsson, 2020). This included changing organisations' priorities, creating new products or services, and radically adapting to remain visible, agile, and productive (Chesbrough, 2020; Kim, 2020; Ivanov, 2020). Based on Ivanov and Dolgui (2020), this pandemic became a test for supply chains on their robustness (i.e., the ability to withstand), flexibility (i.e., the ability to adapt), and recovery (i.e., the ability to restore operations and performance after a disruption) pointing to the central role of resilience in managing the supply chains in this volatile world (Brandon-Jones et al., 2014; Peck, 2005; Pettit et al., 2010; Ponomarov \& Holcomb, 2009).

With the uncertain pace of business conditions, organisations are pressured to find ways or training to cope with stress and adapt to the new changing work environment during the post-pandemic. Above all, these epidemic outbreaks have caused supply chain disruptions whereby managers are caught in a position where they need to manage the long term and short term supply chain risks (Shaharudin et al., 2021). These include long term disruption existence and its unpredictable scaling, simultaneous disruption propagation in the supply chain (i.e., the ripple effect) and epidemic outbreak propagation in the population (i.e., pandemic propagation), and simultaneous disruptions in supply, demand and logistics infrastructure (Ivanov, 2020).

Decision-makers in the supply chain resilience environment have heavily relied on knowledge as it is believed that the more knowledge acquired in managing and controlling both internal and external resources, the more capable managers become of coping with disruptions (Pereira \& Da Silva, 2015). Yet, under this pandemic condition, it may be very challenging to apply the most well-known supply chain resilience mechanisms, such as risk mitigation inventories, subcontracting capacities, or backup supply and transportation infrastructures directly (Ivanov \& Dolgui, 2020). Therefore, the cruciality of supply chain managers' efforts to cope with their companies' supply chain challenges is vital 
during this pandemic (Van Hoek, 2020a, 2020b). On the contrary, the lack of appropriate supply management skills, competencies and capabilities can delay or even halt the business (Heilmann et al., 2011). Hence, this implies that the decision-makers knowledge, skills, abilities, and competencies play a pivotal role in turning things around for the survival and sustainability of the supply chain in their companies.

\section{LITERATURE REVIEW}

\section{Decision-Making Competency}

Decision making refers to the act of choosing an option from a group of alternatives (Takemura, 2014). According to Gunessee and Subramanian (2020), decisions can be seen as strategic or operational in the supply chain context. Strategic supply chain decisions are concerned about designing operations, processes and supply networks, taking a long-term view, while operational decisions relate to regular activities to match demand and supply. Strategic supply chain decision makings include sourcing, production, facility location, distribution and logistics decisions. In addition, it also involved supplier selection where a new approach is used that helps the decision makers select the best supplier with respect to the appropriate criteria and sub-criteria to overcome the uncertainty and ambiguity in the human decision-making process (Ahmad et al., 2016). In contrast, operational supply chain decision-making includes inventory management, demand forecasting, procurement, scheduling and routing decisions (Ivanov et al., 2019).

The Supply Chain (SC) manager competencies span a broad spectrum of areas. This encompasses decision-making skills, management skills, behavioural skills and negotiation skills (Bak, 2019). However, decision-making skills have been highlighted as one of the most critical skills in the context of the supply chain as it includes skills such as planning, organisational skill, flexibility, initiative and problem-solving, bearing in mind they have to respond to the 24/7 global service availability (Giunipero \& Pearcy, 2000; Jordan \& Bak, 2016). The significant characteristic of problem-solving skills is that the skills are crucial in fast-paced, competitive and innovative industries (Bak et al., 2019). Additionally, the SC manager is faced with diverse, complex decisions and activities for which the "old ways of doing things" are not applicable anymore; new approaches and ways of thinking are thus required to stimulate creativity (Williams et al., 1992). Furthermore, due to the fast-changing business environment in terms of increased innovation and competition, the ability to solve problems is not only the critical skill of today. However, it will be most likely relevant for the future as industries adopt more and more technology and innovation, which will affect supply chain managers.

\section{Knowledge Capabilities and Coping Capacity}

The concept of knowledge capabilities refers to a specific combination of the firms' tangible and intangible knowledge assets, competencies and activities that support the generation, use, exchange and sharing of knowledge (Marr et al., 2004; Sappington \& Bedford, 2017; Yang \& Chen, 2007). The literature highlighted the necessity to develop knowledge capabilities congruent with the requirements of customers, suppliers and market participants (Potter et al., 2015; Rangachari, 2009; Wycisk et al., 2008). Three dimensions of knowledge capabilities are identified in the supply chain context. They are exploitation, exploration, and ambidextrous knowledge capabilities (Ogulin et al., 2020).

Organisational learning involves assimilating both new pieces of knowledge (exploration) and using existing knowledge (exploitation). It is argued that exploitation knowledge capabilities must match market and operational requirements. Of note is that, while all organisations need both knowledge exploitation and knowledge exploration capabilities to survive (Stettner \& Lavie, 2014), in organisations that are performing in stable environments, knowledge exploitation plays a principal role, and knowledge exploration plays a supporting role (Cheah \& Tan, 2020; Ogulin et al., 2020).

On the other hand, ambidextrous knowledge capabilities involve developing knowledge exchange capabilities that aim to acquire, analyse and distribute tactical and strategic information, as well as integrating capabilities that involve applying organisational mechanisms to share tacit knowledge among supply chain network players (Blome et al., 2013; Tracey et al., 2005). Ambidextrous knowledge is oriented knowledge within the firm towards the development of exploitation activities and exploration activities for creativity, research and development and sustainable innovation performance. This employee knowledge, which is essential for the adaptation and survival of the firm, can derive in the search for new opportunities (exploration activities) and in the search for more immediate advantages (exploitation activities). Therefore, the development of ambidextrous knowledge (formal and informal) increases creativity by fostering the ability to explore, support the employee capabilities in a particular area, and boost exploitation skills in that area (Levinthal, \& March, 1993). Therefore, ambidextrous knowledge should be a priority for leaders and managers (Halevi, et al., 2015; Turner et al., 2016), as they need to be responsible for marshalling and managing knowledge towards exploration and/or exploitation activities (Munoz-Pascual \& Galende, 2020).

As a whole, from the supply chain perspective, exploitation knowledge capabilities support efficient supply chain networks, exploration knowledge capabilities sustain collaborative supply chain networks, and ambidextrous knowledge capabilities foster agile supply chain networks (Ogulin et al., 2020). In sum, knowledge is closely connected to learning since knowledge is the outcome of learning processes (Argote \& Miron-Spektor, 2011). Moreover, learning involves creating options, experimenting and developing alternative solutions to cope with different degrees of complexity in search of novel solutions (Christopher \& Peck, 2004; Weick \& Sutcliffe, 2007).

Therefore, based on the above arguments, knowledge capabilities have a positive relationship with coping capacity. Thus, the following hypothesis is proposed: 
H1: There is a positive relationship between knowledge capabilities and coping capacity.

\section{Supply Chain Management Skills and Coping Capacity}

The competence in Supply Chain Management (SCM) skills are constantly evolving as they need to adjust and update their capabilities due to the constant encountering of new challenges from the dynamics of the external environment and the introduction of new technologies (Derwik \& Hellström, 2017; McNamara et al., 2003). In the supply chain, management skills include people management, teamwork, leadership skills and collaborative learning. These valuable individual skills can equip supply chain employees to cope with various situations within the expanding scope of the global supply chain (Jordan \& Bak, 2016). The shift in inclusion and importance of management skills resonates with Sohal's (2013) findings, which suggest that practical team-working skills are essential for the successful integration of intermediaries along the supply chain, considering both the local and global partners (Sohal, 2013). Besides that, effective communication (Derwik \& Hellstroof, 2017; Sauber et al., 2008) has also been identified as another critical enabler in the supply chain context. For this reason, supply chain professionals should also be equipped with technical knowledge in order to be able to communicate technical ideas (Carr \& Smeltzer, 2000). Therefore, communication in both written and oral formats at all management levels was deemed necessary (Gammelgaard \& Larson, 2001).

However, with the advancement in IT, supply chain (SC) managers are encouraged to have skills in the information systems required to create the required transformations in supply chain processes (Heyns \& Luke, 2012; Kotzab et al., 2018; Thai et al., 2011). In addition, the SC managers should have some knowledge on the potential benefits of big data and artificial intelligence to supply chain management (Akbari, 2018). Furthermore, with the continued need for supply chain transparency and sustained record keeping, the emergence of blockchain technologies is likely to equip SC managers of the future with skills and knowledge that will create high supply chain visibility (Langley \& Infosys, 2019). However, SC managers may not need to be equipped with the technical skills but should understand the applications and capabilities of blockchain technologies to help design supply chains that leverage the best technologies (Mageto \& Luke, 2020).

In addition, the initiative is considered pivotal for the future as industries are adjusting to the changing dynamics of technology and innovation that influence companies (Van Hoek et al., 2013). This is because the initiative is seen as one of the key drivers to finding new solutions and innovations to continually drive service level up and cost down, requiring supply chain experts to take the initiative to respond. Hence, an initiative that is part of the soft skills is considered vital because it will enhance and stimulate creative thinking by possessing this skill (Bak et al., 2019).

Furthermore, to optimise the role of procurement to achieve added value and competitive advantage for the organisation, SC managers need to develop both internal and external enterprise skills. Internal enterprise skills are related to the overall business and how the different functions interact. These skills will enable SC managers to conduct market analysis effectively, manage internal relationships, global sourcing evaluation, internal change management and planning and organisational skills. At the same time, external enterprise skills are related to the supply chain or network and its stakeholders. These skills will enable the management of external relationships and stakeholder change management (Tassabehji \& Moorhouse, 2008).

On the other hand, skills related to laws and regulations, which include contract management with suppliers, customers and government agencies, are also critical enablers of business operations, and every SC manager should be well versed therein (Prajogo \& Sohal, 2013; Rajakaruna et al., 2017; Wong et al., 2014). Furthermore, national and international laws are essential for SC managers, given the current global nature of SCM where they need to deal with trading partners from different countries which have different laws and regulations relating to supply chain matters (e.g. export/import, tax, chemical substances, etc.) (Murphy \& Poist, 2007; Tatham et al., 2017).

Above all, supply chain managers' skills have been identified as crucial in enhancing business performance (Derwik et al., 2016; Prajogo \& Sohal, 2013; Ronaldo, 2020; Silva et al., 2014). This is because the importance of the supply chain manager's role in coping has been identified as the key to overcoming supply chain challenges ahead (Van Hoek, 2020a, 2020b; Van Hoek et al., 2020).

Based on the findings, SCM competencies and skills have a positive relationship with coping capacity. Hence, the following hypothesis is proposed:

H2: There is a positive relationship between SCM competencies and skills and coping capacity.

\section{Coping Capacity and Decision Making Competency}

Individual coping mechanisms refer to how the individual decision-maker deals with or manages ambiguous situations (Budner, 1962; Kunreuther \& Meszaros, 1997). Coping as a mechanism is a conscious process that is triggered once an ambiguous decision making problem or challenge is encountered (Sjödin et al., 2016). For example, in the supply chain environment, there are four ways the decision-maker handles choices made under ambiguity: sensemaking; (in)tolerance, reference points (assessment) and heuristics (Gunessee \& Subramanian, 2020).

Sensemaking can be defined as making sense of ambiguous situations by searching for meaning, settling on the plausible explanation, and coping with ambiguity (Weick et al., 2005). It can take the form of editing, logical analysis, attribution, and framing to cope with interpretative, causal and evaluative ambiguity. Editing is structuring the available information in a meaningful way to be interpreted, while framing is the subconscious (mental) representations of a decision problem to simplify and make sense of it (Soman, 2004). Attribution refers to assigning meaning to an unclear 
relationship. Instead, logical analysis is a slow, reasoned and coherent approach to interpret and assess ambiguous data (valid to demarcate cause from effect). Finally, probability judgements and weighting are assessments of probabilities where small probabilities are given more prominence (Davis, 2019).

Tolerance of ambiguity, as a coping mechanism for probabilistic and interpretative ambiguities, reflects the decision maker's ambiguity attitudes. Tolerance or intolerance to ambiguity is the decision maker's tendency to interpret or perceive ambiguous situations as desirable and thus opportunities or threats (Budner, 1962). Ambiguity aversion is a decision maker's attitude to avoid ambiguity, as one has a preference for an outcome with known probability over an outcome with unknown probability (Cabantous, 2007; Takemura, 2014). When faced with limited or multiple meanings from information, a decision-maker prefers typically to avoid interpretative ambiguity. In addition, decision-makers exhibit both high and low ambiguity aversion when faced with unknown consequences from their choices (Boloori et al., 2020).

As a means to deal with evaluative and probabilistic ambiguities, reference points are specific values used to evaluate alternative options (in terms of outcomes or probabilities). As the current state/position/view, decision-makers use the status quo as a common reference point. This means decision making is an exercise to evaluate a decision relative to maintaining the status quo (Kunreuther \& Meszaros, 1997). In the face of ambiguity, the illusion of control and being prepared, as connected to reference points, represent a decision maker's belief/confidence of being in control and thus well-prepared in his current position (Schoemaker, 2004).

Heuristics are mental shortcuts that enable decision-makers to make sense of an ambiguous decision-making situation. While several heuristics-based rules govern decision making, there are three that stands out. First, the availability heuristic means making decisions based on what comes to mind and is relevant to the situation that could be something readily available in the decision maker's mind, and thus is used to evaluate outcomes or probabilities (Davenport, 2020; Davis, 2019). Second, the affect heuristic is a decision-maker being influenced by his/her emotions when making decisions. For example, positive and negative emotions can lead decision-makers to focus on their choices' potential benefits and losses (Eckerd \& Bendoly, 2015). Finally, through recognition or take-the-best, fast and frugal heuristics refer to simple shortcuts that use minimum time and knowledge to make quick and adaptive decisions in a situation. It requires limited (recognisable) information search and does not involve much computation (Gigerenzer, 2004).

In behavioural decision theory (BDT), coping mechanisms are broadly defined as heuristic processes that contain information search, attainment of control, and integration of results into future actions as procedural steps (Lipshitz \& Strauss, 1997; Shafir et al., 1993). Coping mechanisms help decision-makers remain actionable in strategic and entrepreneurial contexts subject to environmental unpredictability and variability (Lanivich, 2015). Studies show a positive relationship between coping mechanisms and decision making (Schneckenberg et al., 2017). Based on the above findings, coping capacity has a positive relationship with decision making competency. Hence, the following hypothesis is proposed:

\section{H3: There is a positive relationship between coping capacity and decision-making competency.}

\section{Mediating Role of Coping Capacity}

Coping is defined as thoughts and behaviours used by individuals as a method of managing the internal and external demands of situations appraised as stressful (Folkman \& Lazarus, 1980; Lazarus \& Folkman, 1984), is required when an individual perceives a situation to be personally significant and taxing or exceeding the coping resources available to that individual (Folkman \& Lazarus, 1980). In other words, coping is defined as the cognitive and behavioural efforts constantly changing to master, reduce or tolerate a specific stressor appraised as exceeding one's available resources and abilities (Lazarus \& Folkman, 1984). The study of coping was further expanded by Carver et al. (1989).

According to transactional stress theory (Lazarus \& Folkman, 1984), employees who are less capable of dealing with a stressor are more likely to see it as a threat than a challenge because they anticipate a potential failure in coping. In the same line, stressors are more likely to pose challenges when individuals have better-coping capabilities. This theory that supports coping identifies the process of coping as critical mediators of stressful person-environment relations and their immediate and long-range outcomes. Coping has been well established as a mediator between the stressor and its consequences since the early studies of Folkman and Lazarus (1988). Studies in cognitive and behavioural sciences usually focus on coping mechanisms as individual responses to specific stressors and situated constraints (Skinner et al., 2003).

Coping capacity is considered a fundamental component of one's adaptability to new environments (Hobfoll, 2002). In addition, numerous studies have shown that they play an essential role in understanding employees' responses to change-related stress (Shin, Taylor, \& Seo, 2012; van den Heuvel et al., 2011).

In the organisation literature, coping serves as the mediator between the individual factor and outcome of the studies (Arnout, 2020; Li, Sun, Tao, \& Lee, 2021; Pogere, et al., 2019; Rosman, Sabil, Hassan, \& Kasa, 2020; Zhou et al., 2017). The findings suggested that coping reinforces the effects of individual factors on the outcome. Thus, coping potentially enhances the impact of individual factors on organisational outcomes such as decision making. This suggests that decision-making competency can be improved if knowledge capabilities and SC competencies and skills are used in conjunction with coping capacity. This leads us to the following hypotheses to confirm the mediating role of coping capacity on the previous relationships. Thus, the following hypotheses are proposed:

H4: Coping capacity mediates the relationship between knowledge capabilities and decision-making competency. 
H5: Coping capacity mediates the relationship between SCM skills and competencies and decision-making competency.

\section{RESEARCH GAP}

First, Gunessee and Subramanian (2020) reported that COVID-19 affected almost all existing supply chain decisions. The sudden fluctuation in demand creates ambiguity and uncertainty for supply chains, affecting both forecasting and decision making (Chowdhury et al., 2021; Gunessee \& Subramanian, 2020). This implies a need for studies that help to understand the actual behaviour of decision makers' competency under ambiguity in the supply chain context. Hence, this study intends to fill in the gap by examining the decision making competency in the resilience supply chain environment.

Second, there is a call to investigate the underlying mechanisms and the consequences of the coping mechanisms identified for the survival of firms after post-pandemic (Kraus et al., 2020). Thus, this research intends to investigate how coping capacity affects decision makers' competency in the supply chain resilience environment. Specifically, this study intends to focus on the role of coping capacity in the supply chain domain, particularly at the individual level (Gunessee \& Subramanian, 2020). Therefore, this study intends to plug in the gap by examining the coping capacity for decision making in the resilience supply chain environment.

Third, knowledge plays an integral part in the role of supply chain managers. Although knowledge is critical, there is a lack of existing literature on understanding the roles of knowledge capability that requisite supply chain type (Ogulin et al., 2020). Hence, this study purpose of fill in the gap by examining knowledge capabilities towards coping capacity in the supply chain resilience environment.

Lastly, supply chain managers' competence is constantly evolving as they have to adjust and update their capabilities to meet new challenges (Derwik \& Hellström, 2017; Karttunen, 2018; McNamara et al., 2003). Particularly during the disruption of Covid-19, supply chain managers' encountered difficulties managing risk in the supply chain resilience environment, and their role has been stretched (Van Hoek, 2020a). The role of supply chain management includes strategic sourcing, strategic thinking, sustainability and analytical skills, and new competencies for the future, including big data analytics, automation and e-procurement and holistic supply chain thinking (Bals et al., 2019). With these new functions surfacing, there is a need to refocus on the supply chain manager competency and skills with empirical evidence (Van Hoek, 2020a). Hence, this study intends to plug in the gap by examining the relationship of SCM skills' relationship to coping capacity in the supply chain resilience environment. On the whole, this study addresses the research gaps outlined by Donohue et al. (2020) on both the decision domains and the behavioural domains in the supply chain context.

\section{UNDERPINNING THEORIES}

\section{Behavioural Decisional Theory (BDT)}

The behavioural decisional theory is distinguished from normative decision theory, which models the 'desirable' form of decision-making enshrined as 'rational' decision-making (and thus rational choice theory), as being concerned with describing how people 'actually' make decisions (as descriptive decision models) (Takemura, 2014). Unlike traditional decision theory, which is normative or prescriptive and seeks to find an optimal solution, BDT (although it yields important practical implications) is inherently descriptive, seeking to understand how people actually make decisions (Aldag, 2012). Particularly, behavioural decision making "endeavours to understand the actual influences on actors on making choices" (Mullaly, 2014).

One of the tenets of BDT that makes it distinct is recognising human cognition. Plenty of normative guidance, including tools and methods, aid the rational decision-making process (Hazır, 2015). However, the actual decision behaviour deviates strongly from the rational ideal, as much behavioural decision-making research demonstrates. Several consequences arise as a result. In terms of 'optimising' behaviour, treasured by normative models, it can be altered. As opposed to a reasoned optimising behaviour (maximising or minimising), 'satisficing' human behaviour can be observed, where decision-makers are content with non-optimal choices or choose options they deem acceptable (Davis, 2019; Takemura, 2014). Another significant difference is the resulting 'cognitive biases' and thus sub-optimal decisions (Davenport, 2020; Roberto et al., 2006). Therefore, research of BDT suggests that people's decision-making process is extremely situation-dependent and that various psychological processes develop (Takemura, 2014).

\section{Competency Model}

The competency model can be traced back to the groundbreaking work of David McClelland (1973), Boyatzis (1982), Spencer and Spencer (1993), and many others in the field (Ozcelik \& Ferman, 2006). Competencies are defined as skills, knowledge, abilities and attributes characteristics that enable people to perform their jobs successfully (Spicer, 2009). According to Marrelli (1998), competencies are measurable human capabilities required for practical work performance demands. It can also be viewed as a combination of tacit and explicit knowledge, behaviour and skills that gives someone the potential for effectiveness in their task performance (Draganidis \& Mentzas, 2006). However, based on Dubois (1998), these competencies go beyond those characteristics of knowledge and skills, mindsets, thought patterns, and the like that, when used either singularly or in various combinations, result in successful performance.

Furthermore, competency models are effective measurement tools that help align employees' internal behaviour and skills with the organisation's strategic direction as a whole. To sum, this competency model is a detailed description of behaviours that employees require in order to have the ability to be effective in a job (Mansfield, 1996). 


\section{RESEARCH FRAMEWORK}

By integrating the Behavioral Decisional Theory (BDT) (Takemura, 2014) and competency model as the underpinning theories, a framework is proposed with the emphasis on coping capacity as the mediator that links the critical factors of knowledge capabilities and SCM skills with decision making competency in supply chain resilience environment. Hence, the integration of the two theories will help guide the development of this research framework and strengthen the causal effect of each variable. As a result, this study adopts the competency model as the basis for this research to address the critical set of related knowledge, skills and attributes that can contribute to the decision making competency.

Based on the KSA framework, knowledge capabilities are categorised under the related knowledge for this study related to the information domain. These knowledge capabilities cover the exploitative, exploration and ambidextrous knowledge, which can enhance their decision making competency in the workplace. In comparison, the sets of skills for this study refer to the SCM skills. These SCM skills are critical sets of abilities that each supply chain manager needs to carry out their daily functions effectively.

Lastly, coping capacity relates to the personal characteristics or traits of an individual that are considered the attributes under the KSA framework of competency for this study. Finally, coping capacity refers to the adaptive readiness or willingness to adapt to and proactively respond to changes (Coetzee, 2021; Konstant, 2020). All of these KSA elements are crucial to influencing the decision making competency.

Integrating the relevant theoretical perspectives helps to develop a more comprehensive understanding of the mixed effects the competency model and behavioral decision theory (BDT) (Takemura, 2014) towards decision-making competency in the supply chain resilience environment. This study will help confirm the combination effect of knowledge, skills or attributes that can best influence our decision-making competency, which will help us further understand how behaviour deviates from normative theories. Understanding the proactive reduction of risks beyond the usual risk response can help lower the exposure of risk in a supply chain resilience environment. Research in this category often focuses on identifying whether, when, and how behaviour deviates from normative theories and provide a deeper understanding of why such deviations occur. Figure 1 illustrates the proposed research framework.

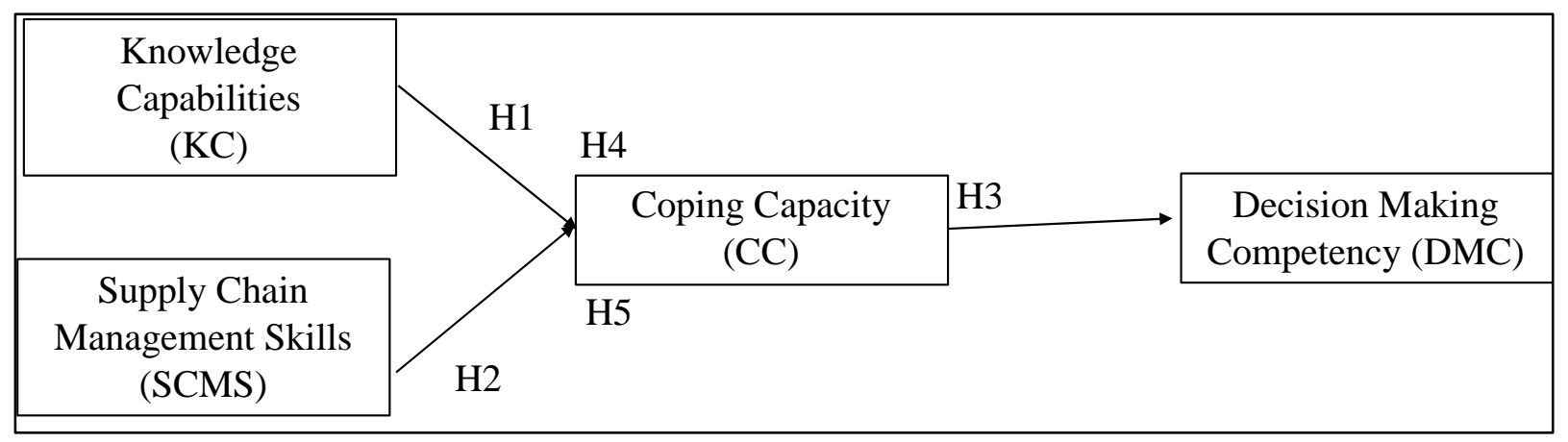

Figure 1. Proposed Research Framework

\section{Objective of Research}

This research has the following objectives:

1. To examine the relationship between knowledge capabilities and supply chain management skills with decision making competency in a supply chain resilience environment.

2. To investigate the relationship between coping capacity and decision making competency in a supply chain resilience environment.

3. To investigate the mediating effect of coping capacity on the relationship between knowledge capabilities and supply chain management skills with decision making competency in a supply chain resilience environment.

\section{RESEARCH METHODOLOGY}

The online structured survey questionnaire will be emailed to the supply chain professionals, the target population for this research. The supply chain professionals work in manufacturing firms that mainly focus on the seven Malaysian industrial states. These seven states include Penang, Kedah, Perak, Selangor, Negeri Sembilan, Melaka and Johor, which reported the highest GDP contribution in Malaysia coming from the manufacturing sector from 2019 to 2020 (Department of Statistics Malaysia, 2021), reflecting the homogeneity of the economic environment. The Federation of Malaysian Manufacturers (FMM) Directory that consists of 3,365 manufacturing firms, will be used for this research as the sampling frame (Federation of Malaysian Manufacturers Directory, 2020). The minimum sample size for this study is 230. The purposive technique is chosen for this study because it requires responses from supply chain professionals who are in the 
managerial level and above working in manufacturing firms, as they are heavily involved in daily strategic and operational decision making.

The survey questionnaire set consists of five main sections with a total of 73 items. A combination of a 5-point Likert scale and a 7-point Likert scale will be adopted for this study. A 23-items scale for DMC will be adopted from Siebert and Kunz (2015). As for measuring KC and CC, 13 items will be adopted from Schnellbächer and Heidenreich (2020) and 19 items from Coetzee et al. (2020). As for SCMS, an 18-items scale will be adapted from Prajago and Sohal (2013). Finally, the data will be cleaned and recoded using the SPSS. The measurement model will be assessed for constructs validity and reliability before the relationship of the structural model will be analysed for hypothesis testing, effect size, predictive relevance and mediation effect using Smart-PLS.

\section{CONCLUSION}

In summary, this research aims to bridge the knowledge capabilities and SCM skills with decision making competency by considering coping capacity as the mediator in the supply chain resilience environment of the manufacturing companies in Malaysia. It is believed that this framework can provide decision-makers with a new and fresh insight on an integrative framework of some of the key predictors and outcomes of decision making competency in the supply chain environment. Moreover, we assume that the expansion will help offer a cohesive body of knowledge to better predict and improve human decisions in supply chains. The novelty of this study lies in integrating the framework and identifying the related coping capacity that influences decision making competency among the supply chain management in the Malaysian manufacturing companies. Understanding the supply chain decision-making in operations can help de-risk the supply chain beyond the usual risk response into the proactive reduction of risks for future supply chain sustainability.

\section{REFERENCES}

Ahmad, N., Kasim, M. M., \& Rajoo, S. S. K. (2016). Supplier selection using a fuzzy multi-criteria method. International Journal of Industrial Management, 2, 61-71.

Akbari, M. (2018). 'Logistics outsourcing: A structured literature review', Benchmarking: An International Journal,25 (5), 1548-1580. https://doi.org/10.1108/BIJ-04-2017-0066

Araz, O.M., Choi, T.-M., Olson, D., \& Salman, F.S. (2020). Data Analytics for Operational Risk Management. Decision Sciences, 51(6), 1316-1319.

Argote, L., \& Miron-Spektor, E. (2011). "Organisational learning: From experience to knowledge", Organization Science, 22, 1123- 1137.

Arnout, B. A. (2020). A structural equation model relating unemployment stress, spiritual intelligence, and mental health components: Mediators of coping mechanism. Journal of Public Affairs, 20(2), e2025.

Bak, O., Jordan, C., \& Midgley, J. (2019). The adoption of soft skills in supply chain and understanding their current role in supply chain management skills agenda : A UK perspective. Benchmarking: An International Journal. 26(3), 1063-1079.

Blome, C., Schönherr, T. \& Rexhausen, D. (2013). "Antecedents and enablers of supply chain agility and its effect on performance: a dynamic capabilities perspective", International Journal of Production Research, 51(4), 12951318.

Boloori, A., Saghafian, S., Chakkera, H. A., \& Cook, C. B. (2020). Data-driven management of post-transplant medications: An ambiguous partially observable markov decision process approach. Manufacturing \& Service Operations Management, 22(5), 1066-1087.

Boyatzis, R. E. (1982). The competent manager: A model for effective performance. John Wiley \& Sons.

Brandon-Jones, E., Squire, B., Autry, C. W., \& Petersen, K. J. (2014). A contingent resource-based perspective of supply chain resilience and robustness. Journal of Supply Chain Management, 50(3), 55-73.

Budner, S. (1962). "Intolerance of ambiguity as a personality variable", Journal of Personality, 30(1), 29-50.

Carr, A.S., \& Smeltzer, L.R. (2000). "An empirical study of the relationship among purchasing skills and strategic purchasing, financial performance, and supplier responsiveness", Journal of Supply Chain Management, 36(3), 40-54.

Cheah, S. C., \& Tan, C. L. (2020). Knowledge Management, Organizational Ambidexterity, and Manufacturing Performance in the Era of Industry 4.0:A Proposed Model. International Journal of Industrial Management, 5, 10-19. https://doi.org/10.15282/ijim.5.0.2020.5696

Chesbrough, H. (2020). To recover faster from Covid-19, open up: Managerial implications from an open innovation perspective. Industrial Marketing Management, 88, 410-413. https://doi.org/10.1016/j.indmarman.2020.04.010

Chowdhury, P., Kumar Paul, S., Kaisar, S., \& Abdul Moktadir, M. (2021). COVID-19 pandemic related supply chain studies: a systematic review. Transportation Research Part E: Logistics and Transportation Review, (February), 102271. https://doi.org/10.1016/j.tre.2021.102271

Coetzee, M., Bester, M. S., Ferreira, N., \& Potgieter, I. L. (2020). Facets of career agility as explanatory mechanisms of employees' career adaptability. African Journal of Career Development, 2(1), 1-7. 
Coetzee, M. (2021). Career Wellbeing and Career Agility as Coping Attributes in the Modern Career Space. In N Ferreira, I.L. Potgieter, \& M. Coetzee (Eds.), Agile coping in the Digital Workplace (pp. 35-51): Emerging issues for $\quad$ research and practice. Springer Nature

Davenport, T.H. (2020). "How to Make Better Decisions About Coronavirus", MIT Sloan Management Review, Column, April 8

Davis, A.M. (2019). "Biases in Individual Decision-Making", Donohue K, Katok E, Leider S. (Eds). The Handbook of Behavioral Operations, Wiley.

Department of Statistics Malaysia (2021). Gross Domestic Product (GDP) by State. https://www.dosm.gov.my/v1/index.php?r=column/cthemeByCat\&cat=491\&bul_id=YnhhZ2g5QlpZWG9RcVN wTGhLaHE4UT09\&menu_id=TE5CRUZCblh4ZTZMODZIbmk2aWRRQT09

Derwik, P., Hellström, D., \& Karlsson, S. (2016). Manager competences in logistics and supply chain practice. Journal of Business Research, 69(11), 4820-4825.

Derwik, P., \& Hellström, D. (2017). Competence in supply chain management: a systematic review. Supply Chain Management: An International Journal. 22(2), 200-218. https://doi.org/10.1108/SCM-09-2016-0324

Donohue, K., Özer, Ö., \& Zheng, Y. (2020). Behavioral operations: past, present, and future. Manufacturing \& Service Operations Management, 22(1), 191-202.

Draganidis, \& Mentzas. (2006). "Competency Based Management; a review of Systems and approaches", Information Management \& Computer Security, 14(1), 51- 64.

Dubois, D. D. (Ed.). (1998). The competency casebook: Twelve studies in competency-based performance improvement. Human Resource Development.

Eckerd, S., \& Bendoly, E. (2015). "The Study of Behavioral Operations", Bendoly, E., Wezelm W.V. and Bachrach, D.G. (Eds). The Handbook of Behavioral Operations Management: Social and Psychological Dynamics in Production and Service Settings, pp. 33-43.

Ennis, M. R. (2008). Competency models: a review of the literature and the role of the employment and training administration (ETA) (pp. 1-25). Office of Policy Development and Research, Employment and Training Administration, US Department of Labor.

Federation of Malaysian Manufacturers Directory (2020), "FMM directory of Malaysian industries", available at: www.fmm.org.my/ (accessed July 3, 2021).

Folkman, S., \& Lazarus, R. S. (1980). An analysis of coping in a middle-aged community sample. Journal of health and social behavior, 219-239.

Folkman, S., \& Lazarus, R. S. (1988). Coping as a mediator of emotion. Journal of personality and social psychology, 54(3), 466.

Gammelgaard, B., \& Larson, P. D. (2001). Logistics skills and competencies for supply chain management. Journal of Business logistics, 22(2), 27-50.

Giunipero, L. C., \& Pearcy, D. H. (2000). World-class purchasing skills: an empirical investigation. Journal of Supply Chain Management, 36(3), 4-13.

Gunessee, S., \& Subramanian, N. (2020). Ambiguity and its coping mechanisms in supply chains lessons from the Covid- 19 pandemic and natural disasters. International Journal of Operations \& Production Management.

Halevi, M. Y., Carmeli, A., \& Brueller, N. N. (2015). Ambidexterity in SBUs: TMT behavioral integration and environmental dynamism. Human Resource Management, 54(S1), 223-238.

Heilmann, P., Lintukangas, K., \& Peltola, S. (2011). 'Competence areas and knowledge gaps in supply management', International Journal Procurement Management, 4(6), 642-660.

Heyns, G., \& Luke, R. (2012). 'Skills requirements in the supply chain industry in South Africa', Journal of Transport and Supply Chain Management, 6(1), 107-125. https://doi.org/10.4102/jtscm.v6i1.34

Hobfoll, S. E. (2002). Social and psychological resources and adaptation. Review of General Psychology, 6, $307-324$. https://doi.org/10.1037/1089-2680.6.4.307

Ivanov, D. (2020). Predicting the impacts of epidemic outbreaks on global supply chains: A simulation-based analysis on the coronavirus outbreak (COVID-19/SARS-CoV-2) case. Transportation Research Part E: Logistics and Transportation Review, 136, 101922

Ivanov, D., \& Das, A. (2020) 'Coronavirus (COVID-19/SARS-CoV-2) and supply chain resilience: a research note', International Journal Integrated Supply Management, 13(1), 90-102.

Ivanov, D., \& Dolgui, A. (2020). OR-methods for coping with the ripple effect in supply chains during COVID-19 pandemic: Managerial insights and research implications. International Journal of Production Economics, 107921.

Jordan, C., \& Bak, O. (2016). The growing scale and scope of the supply chain: a reflection on supply chain graduate skills. Supply Chain Management: An International Journal.

Karttunen, E. (2018). Purchasing and supply management skills revisited: an extensive literature review. Benchmarking: An International Journal.

Kim, R. Y. (2020). The impact of COVID-19 on consumers: Preparing for digital sales. IEEE Engineering Management Review. 1-16. https://doi.org/10.1109/EMR.2020.2990115

Kotzab, H., Teller, C., Bourlakis, M., \& Wünsche, S. (2018). 'Key competences of logistics and SCM professionals The lifelong learning perspective', Supply Chain Management: An International Journal, 23(1), 50-64. https://doi.org/10.1108/ SCM-02-2017-0079 
Kraus, S., Clauss, T., Breier, M., Gast, J., Zardini, A., \& Tiberius, V. (2020). The economics of COVID-

19: initial empirical evidence on how family firms in five European countries cope with the corona crisis. International Journal of Entrepreneurial Behavior \& Research.

Kunreuther, H. and Meszaros, J. (1997), "Organisational choice under ambiguity: Decision making in the chemical industry following Bhopal", Shapira, Z. (Ed.). Organisational Decision Making, Cambridge University Press, Cambridge, UK, pp. 61-80.

Langley, C.J., \& Infosys. (2019). 2019 Third-party logistics (3PL) study - The state of logistics outsourcing: Result and findings of the 23rd annual study, Infosys Consulting, viewed 16 March 2019, from http://www.3plstudy.com/3pl2017download.php.

Lanivich, S.E. (2015) The RICH entrepreneur: using conservation of resources theory in Contexts of uncertainty. Entrepreneurship Theory and Practice, 39(4), 863-894.

Lazarus, R. S., \& Folkman, S. (1984). Stress, appraisal, and coping. Springer publishing company.

Levinthal, D. A., \& March, J. G. (1993). The myopia of learning. Strategic Management Journal, 14(S2), 95-112.

Li, J. Li, Y., Sun, R., Tao, W., \& Lee, Y. (2021). Employee coping with organisational change in the face of a pandemic: The role of transparent internal communication. Public Relations Review, 47(1), 101984.

Lipshitz, R. and Strauss, O. (1997) Coping with uncertainty: a naturalistic decision-making analysis. Organisational Behavior and Human Decision Processes, 69(2), 149-163.

Mageto, J., \& Luke, R. (2020). Skills frameworks: A focus on supply chains, Journal of Transport and Supply Chain Management, 14(0), a458. https://doi.org/10.4102/ jtscm.v14i0.458

Maree, J. G. K. (2020). Renewing career counselling to promote the facilitation of sustainable decent work across the globe. South African Journal of Education, 40, 1-3.

Marr, B., Schiuma, G. and Neely, A. (2004), "Intellectual capital-defining key performance indicators for organisational knowledge assets", Business Process Management Journal, 10(5), 551-569.

Mansfield, R.S. (1996). Building Competency Models: Approaches for HR Professionals. Human Resource Management, 35(1), 7-18.

McNamara, G., Vaaler, P.M., \& Devers, C. (2003). "Same as it ever was: the search for evidence of increasing hypercompetition", Strategic Management Journal, 24(3), 261-278.

Munoz-Pascual, L., \& Galende, J. (2020). Ambidextrous Knowledge and Learning Capability: The Magic Potion for Employee Creativity and Sustainable Innovation Performance. Sustainability, 12(10), 3966.

Murphy, P.R., \& Poist, R.F. (2007). 'Skill requirements of senior-level logisticians: A longitudinal assessment', Supply Chain Management: An International Journal, 12(6), 423-431. https://doi.org/10.1108/13598540710826353

Ogulin, R., Guzman, G., \& Nuwangi, S. M. (2020). Knowledge capabilities in supply chain networks: a taxonomy. Journal of Knowledge Management. 24(3), 655-674. https://doi.org/10.1108/JKM-06-2019-0266

Peck, H. (2005). Drivers of supply chain vulnerability: An integrated framework. International Journal of Physical Distribution \& Logistics Management, 35(4), 210-232.

Pereira, C. R., \& Da Silva, A. L. (2015). Key Organisational Factors to Building Supply Chain Resilience: a Multiple Case Study of Buyers and Suppliers. Journal of Operations and Supply Chain Management, 8(2), 77-95.

Pettit, T. J., Fiksel, J., \& Croxton, K. L. (2010). Ensuring supply chain resilience: development of a conceptual framework. Journal of Business Logistics, 31(1), 1-21.

Pogere, E. F., López-Sangil, M. C., García-Señorán, M. M., \& González, A. (2019). Teachers’ job stressors and coping strategies: Their structural relationships with emotional exhaustion and autonomy support. Teaching and Teacher Education, 85, 269-280.

Ponomarov, S.Y., \& Holcomb, M.C. (2009). 'Understanding the concept of supply chain resilience', The International Journal of Logistics Management, 20(1),124-143.

Prajogo, D., \& Sohal, A. (2013). Supply chain professionals: A study of competencies, use of technologies, and future challenges. International Journal of Operations \& Production Management, 33(11-12), 1532-1554.

Roberto, M., Bohmer, R.M.J., \& Edmondson, A.C. (2006). "Facing ambiguous threats", Harvard Business Review, November, 106-113.

Ronaldo, R. (2020). Measuring the performance of poultry business through effective supply chain management skills. Uncertain Supply Chain Management, 8(1), 55-66. https://doi.org/10.5267/j.uscm.2019.8.006

Rosman, M., Sabil, S., Hassan, Z., \& Kasa, M. (2020). Organisational Factors and Work-Life Balance among Policewomen in Sarawak: Emotion Based Coping Strategy as Mediator. International Journal of Academic Research in Business and Social Sciences, 10(1).

Sappington, J. and Bedford, D. A. (2017). "Assessment of intellectual capital of library and information professionals". Proceedings of the Association for Information Science and Technology,54(1), 798-799.

Schneckenberg, D., Velamuri, V. K., Comberg, C., \& Spieth, P. (2017). Business model innovation and decision making: uncovering mechanisms for coping with uncertainty. R\&D Management, 47(3), 404-419.

Schnellbächer, B., \& Heidenreich, S. (2020). The role of individual ambidexterity for organisational performance: examining effects of ambidextrous knowledge seeking and offering. Journal of Technology Transfer, 45(5), 1535-1561. https://doi.org/10.1007/s10961-020-09781-x

Shafir, E., Simonson, I., and Tversky, A. (1993) Reason- based choice. Cognition, 49(1), 11-36. 
Shin, J., Taylor, M. S., \& Seo, M. G. (2012). Resources for change: The relationships of organisational inducements and psychological resilience to employees' attitudes and behaviors toward organisational change. Academy of Management journal, 55(3), 727-748.

Siebert, J., \& Kunz, R. (2015). Developing and validating the multidimensional proactive decision-making scale. European Journal of Operational Research, 249(3), 864-877. https://doi.org/10.1016/j.ejor.2015.06.066

Shaharudin, M. S., Suhaimi, S., Fernando, Y., \& Husain, W. A. F. W. (2021). Improvement of Green Procurement Performance in the Global Supply Chain: Evidence from Enterprise Resource Planning and Social Network Analysis. International Journal of Industrial Management, 10, 173-194.

Sjödin, D.R., Parida, V. \& Wincent, J. (2016). "Value co-creation process of integrated product-services: Effect of role ambiguities and relational coping strategies", Industrial Marketing Management, 56, 108-119.

Skinner, E.A., Edge, K., Altman, J., and Sherwood, H. (2003) Searching for the structure of coping: a review and critique of category systems for classifying ways of coping. Psychological Bulletin, 129, 2, 216-269.

Sohal, A. S. (2013). Developing competencies of supply chain professionals in Australia: collaboration between businesses, universities and industry associations. Supply Chain Management: An International Journal.

Soman, D. (2004). "Framing, Loss Aversion, and Mental Accounting", Koehler, D.J. and Harvey, N. (Eds). Blackwell Handbook of Judgment and Decision Making, Blackwell Publishing, UK, pp. 370-398.

Spencer, L. and Spencer, S. (1993). Competence at Work: A Model for Superior Performance (New York: Wiley). Amref Competency report, 2009

Spicer. (2009), "Building a Competency Model", HR Magazine, 54(4), 34- 36.

Stettner, U. and Lavie, D. (2014). "Ambidexterity under scrutiny: exploration and exploitation via internal organisation, alliances, and acquisitions", Strategic Management Journal, 35(13), 1903-1929.

Tatham, P., Wu, Y., Kovács, G., \& Butcher, T. (2017). 'Supply chain management skills to sense and seize opportunities', The International Journal of Logistics Management,28(2), 266-289. https://doi.org/10.1108/IJLM04-2014- 0066

Takemura, K. (2014). Behavioral Decision Theory: Psychological and Mathematical Descriptions of Human Choice Behavior. Springer.

Turner, N., Kutsch, E., \& Leybourne, S. A. (2016). Rethinking project reliability using the ambidexterity and mindfulness perspectives. International Journal of Managing Projects in Business.

van den Heuvel C, Alison L, Crego J (2011) How uncertainty and accountability can derail strategic 'save life' decisions in counter-terrorism simulations: a descriptive model of choice deferral and omission bias. Journal Behavior Decision Making. doi: 10.1002/bdm.723

Van Hoek, R., Wagner, B., Lorentz, H., Töyli, J., Solakivi, T., \& Ojala, L. (2013). Priorities and determinants for supply chain management skills development in manufacturing firms. Supply Chain Management: An International Journal.

Van Hoek, R. (2020a). Research opportunities for a more resilient post-COVID-19 supply chain-closing the gap between research findings and industry practice. International Journal of Operations \& Production Management.

Van Hoek, R. (2020b). "Supply Chain Risks - Insights from Supply Chain Change Management, Total Cost of Ownership and Supplier Segmentation Theory." Logistics 4(4):341. https://doi.org/10.3390/logistics4040023.

Van Hoek, R., Gibson, B., \& Johnson, M. (2020). Talent Management For a Post-COVID-19 Supply Chain-The Critical Role for Managers. Journal of Business Logistics.

Verma, S., \& Gustafsson, A. (2020). Investigating the emerging COVID-19 research trends in the field of business and management: A bibliometric analysis approach. Journal of Business Research, 118, 253-261.

Weick, K. E., Sutcliffe, K. M., \& Obstfeld, D. (2005), "Organising and the process of sensemaking", Organization Science, 16(4), 409-421.

Weick, K. E., \& Sutcliffe, K. M. (2007). Managing the unexpected: Resilient performance in the age of uncertainty (2nd ed.). Jossey-Bass.

Williams, A. J., Lacy, S., \& Smith, W. C. (1992). Purchasing's role in value analysis: Lessons from creative problem solving. International Journal of Purchasing and Materials Management, 28(2), 37-42.

Wong, Y.C., Grant, B.D., Allan, B., \& Jasiuvian, I. (2014). 'Logistics and supply chain education and jobs: A study of UK markets', The International Journal of Logistics Management, 25(3), 537-552. https://doi.org/10.1108/IJLM-01-2013-0003

Zhou, Y., Li, D., Li, X., Wang, Y., \& Zhao, L. (2017). Big five personality and adolescent Internet addiction: The mediating role of coping style. Addictive behaviors, 64, 42-48.

\section{CONFLICT OF INTEREST}

The author(s), as noted, certify that they have NO affiliations with or involvement in any organisation or agency with any financial interest (such as honoraria; educational grants; participation in speakers' bureaus; membership, jobs, consultancies, stock ownership, or other equity interest; and expert testimony or patent-licensing arrangements), or nonfinancial interest (such as personal or professional relationships, affiliations, expertise or beliefs) in the subject matter or materials addressed in this manuscript. 


\section{AUTHORS' BIOGRAPHY}

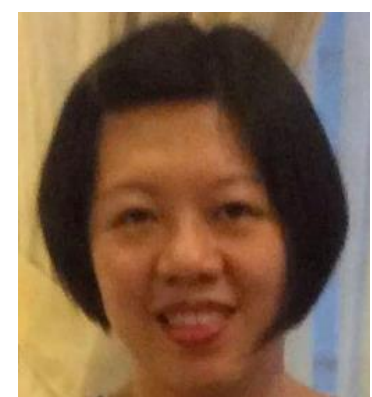

Author's Full Name: Khor Lay Kheng

Author's Email: khorlaykheng@ gmail.com

Author's Professional Bio: Khor Lay Kheng is a Ph.D. scholar attached to the Graduate School of Business at Universiti Sains Malaysia. She holds a Bachelor of Commerce degree from Deakin University, Australia and a Master of Arts (Management) degree from Universiti Sains Malaysia. She has more than 10 years of experience with two multinational companies and 2 years in the service industry. Her research focus is on behavioral operations management, supply chain management, leadership, human resource management and occupational safety \& health (OSH).

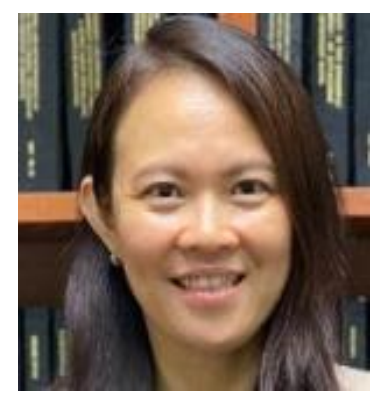

Author's Full Name: Dr. Tan Cheng Ling

Author's Email: tanchengling@usm.my

Author's Professional Bio: Dr. Tan Cheng Ling is currently an Associate Professor at the Graduate School of Business at the Universiti Sains Malaysia. Previously, she was a global supply chain quality consultant, as well as a quality department manager for more than 10 years with two multinational companies in Malaysia. Her research focus is on operations management, innovation, supply chain management, knowledge management and behavioural in operations management. 